\title{
RESEARCH
}

Open Access

\section{Reliability and validity of three questionnaires measuring context-specific sedentary behaviour and associated correlates in adolescents, adults and older adults}

\author{
Cedric Busschaert ${ }^{1,3}$, Ilse De Bourdeaudhuij ${ }^{1^{*}}$, Veerle Van Holle ${ }^{1,3}$, Sebastien FM Chastin ${ }^{2}$, Greet Cardon ${ }^{1}$
} and Katrien De Cocker ${ }^{1,3}$

\begin{abstract}
Background: Reliable and valid measures of total sedentary time, context-specific sedentary behaviour (SB) and its potential correlates are useful for the development of future interventions. The purpose was to examine test-retest reliability and criterion validity of three newly developed questionnaires on total sedentary time, context-specific SB and its potential correlates in adolescents, adults and older adults.

Methods: Reliability and validity was tested in six different samples of Flemish (Belgium) residents. For the reliability study, 20 adolescents, 22 adults and 20 older adults filled out the age-specific SB questionnaire twice. Test-retest reliability was analysed using Kappa coefficients, Intraclass Correlation Coefficients and/or percentage agreement, separately for the three age groups. For the validity study, data were retrieved from 62 adolescents, 33 adults and 33 older adults, with activPAL ${ }^{\mathrm{TM}}$ as criterion measure. Spearman correlations and Bland-Altman plots (or nonparametric approach) were used to analyse criterion validity, separately for the three age groups and for weekday, weekend day and average day.

Results: The test-retest reliability for self-reported total sedentary time indicated following values: ICC $=0.37-0.67$ in adolescents; ICC $=0.73-0.77$ in adults; ICC $=0.68-0.80$ in older adults. Item-specific reliability results (e.g. context-specific SB and its potential correlates) showed good-to-excellent reliability in $67.94 \%, 68.90 \%$ and $66.38 \%$ of the items in adolescents, adults and older adults respectively. All items belonging to sedentary-related equipment and simultaneous SB showed good reliability. The sections of the questionnaire with lowest reliability were: context-specific SB (adolescents), potential correlates of computer use (adults) and potential correlates of motorized transport (older adults). Spearman correlations between self-reported total sedentary time and the activPAL ${ }^{\mathrm{TM}}$ were different for each age group: $\rho=0.02-0.42$ (adolescents), $\rho=0.06-0.52$ (adults), $\rho=0.38-0.50$ (older adults). Participants over-reported total sedentary time (except for weekend day in older adults) compared to the activPAL ${ }^{\mathrm{TM}}$, for weekday, weekend day and average day respectively by $+57.05 \%,+46.29 \%,+53.34 \%$ in adolescents; $+40.40 \%,+19.15 \%,+32.89 \%$ in adults; $+10.10 \%,-6.24 \%,+4.11 \%$ in older adults.
\end{abstract}

Conclusions: The questionnaires showed acceptable test-retest reliability and criterion validity. However, over-reporting of total SB was noticeable in adolescents and adults. Nevertheless, these questionnaires will be useful in getting context-specific information on SB.

Keywords: Adolescents, Adults, Older adults, Questionnaire, Validity, Reliability, Sedentary behaviour

\footnotetext{
*Correspondence: Ilse.Debourdeaudhuij@UGent.be

'Department Movement and Sport Sciences, Ghent University,

Watersportlaan 2, B-9000 Ghent, Belgium

Full list of author information is available at the end of the article
}

(c) 2015 Busschaert et al. Open Access This article is distributed under the terms of the Creative Commons Attribution 4.0 International License (http://creativecommons.org/licenses/by/4.0/), which permits unrestricted use, distribution, and reproduction in any medium, provided you give appropriate credit to the original author(s) and the source, provide a link to the Creative Commons license, and indicate if changes were made. The Creative Commons Public Domain Dedication waiver (http://creativecommons.org/publicdomain/zero/1.0/) applies to the data made available in this article, unless otherwise stated. 


\section{Background}

Sedentary behaviour (SB), defined as any waking activity characterized by an energy expenditure $\leq 1.5$ metabolic equivalents (METs) performed in a sitting or reclining posture [1], is ubiquitous in daily life among all age groups. Independent of physical activity (PA), SB is associated with physical and mental health risks in adolescents [2, 3], adults [2], and older adults [4, 5]. Despite these health-related consequences, Belgian adolescents, adults and older adults have high levels of daily objectively

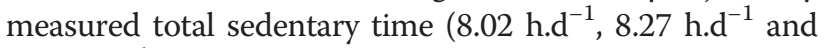
9.67 h. $\mathrm{d}^{-1}$ respectively), which is similar in duration to their international peers $\left(9.00\right.$ h.d $\mathrm{d}^{-1}, 9.64 \mathrm{~h} . \mathrm{d}^{-1}$ and 9.00 h.d $\mathrm{d}^{-1}$ respectively) [6-10].

$\mathrm{SB}$ is a complex behaviour as it is habitual in nature and occurs in multiple contexts [11], across four domains [12] (e.g. watching TV, sitting at work, during motorized transport or while doing household tasks) [13]. The contexts of SB are similar for adolescents, adults and older adults (e.g. reading and TV-viewing), but there are also important age-specific contexts, e.g. school-context for adolescents, work-context for adults and sitting while caring (grandchildren) for older adults. As a result, measuring context-specific SB is important. Measurements of context-specific SB will increase the effectiveness of future interventions by identifying highrisk SB contexts which can be targeted. Furthermore, gathering information on all relevant contexts of SB, based on a consensus taxonomy [11], will provide an estimation of total sitting time, which will be valuable in identifying highly sedentary subgroups in large-scale observational studies in which the use of objective measurement devices is still not practical due to cost or participant burden $[7,11,13,14]$.

In addition to context-specific SB, it is also important to determine the potential correlates of context-specific SB, for different age groups. Future interventions will only be effective if they target the reasons why people tend to sit more in specific contexts, but currently there is a dearth of information about these correlates [15]. To date, research on correlates of SB has focused on TV viewing, computer use and playing videogames or $\mathrm{SB}$ in general $[16,17]$. Focussing solely on correlates of screenrelated behaviour may limit interventions designed to evoke meaningful changes in total SB. On the other hand, gathering correlates of total SB is relevant [12], but is too broad to design more-effective interventions in the future. Questionnaires incorporating potential correlates of all specific contexts of SB are needed to develop more effective interventions. Previous studies on correlates concentrated on socio-demographic correlates together with one other type of variables, for example biological or behavioural correlates. Owen et al. [12] noted the need for future research to identify correlates at multiple levels, including individual; social; organizational/community; environmental; and policy levels. In addition, previous correlate studies focused on a small number of SB contexts. The existing literature on correlates of SB are different for adolescents, adults and older adults [12]. To our knowledge there are currently no questionnaires identifying potential social-ecological correlates of all relevant contexts of SB in adolescents, adults and older adults.

Gathering information on context-specific SB and its correlates is mostly done using self-report measurements such as questionnaires or diaries [13]. SB questionnaires can be used from the age of 12 (i.e. adolescents) and are commonly used in large-scale observational studies [18]. In addition, questionnaires (self-report) are cost-effective, easily accessible to a large proportion of the population and participant burden is relatively low [19]. However, questionnaires can be susceptible to bias caused by cultural norms, social desirability and/or recall $[19,20]$. Despite these drawbacks, questionnaires are more pragmatic and scalable than objective measurement tools in largescale observational studies.

To address these gaps, we developed three age-specific questionnaires (adolescents, adults and older adults) in order to identify context-specific SB and its determinants/correlates. These age-specific questionnaires were based on the 'ecologic model of four domains of SB' [12], the Theory of Planned Behaviour (TPB) [21] and a consensus taxonomy of SBs [11], as they include multiple SB contexts (SB domains: leisure time, household, occupation and transport) and their potential correlates at multiple levels (e.g. attitude and subjective norm of $\mathrm{TPB})$. The main goal of the current study was to test if the newly developed questionnaires were reliable and valid to determine context-specific $\mathrm{SB}$ and its potential correlates and total sedentary time in three different age groups. The objectives of the current study were to: (a) analyse the test-retest reliability of questionnaires designed to assess self-reported total sedentary time (for weekdays, weekend days and average days), contextspecific SBs (for weekdays and weekend days) and their potential social-ecological correlates in adolescents, adults and older adults; and (b) assess the criterion validity of these questionnaires for self-reported total weekday, weekend day and average day sedentary time.

\section{Methods}

\section{Subjects and procedures}

Sampling approaches were different for the reliability and validity study. In both studies, data were collected in 2013-2014 among adolescents, adults and older adults. An information letter or a verbal explanation was provided to adolescents, adults and older adults participating in the studies. For adolescents parental permission 
was sought. The studies were approved by the Ghent University Hospital Ethics Committee.

\section{Test-retest reliability}

Twenty adolescents, 22 adults and 20 older adults, living in Flanders (Belgium), were recruited by using purposeful convenience sampling. Relatives and acquaintances of the research team were contacted to participate in the test-retest reliability study. Additional participants were recruited through purposive snowball sampling, so that participants with different backgrounds (e.g. living environment and socio-economic status) were invited to participate in the study. All participants completed the same questionnaire on context-specific SB and its potential correlates twice. In line with Duncan et al. [22], at least a 6 days interval elapsed between both measurements (mean interval: adolescents $=16 \pm 9$ days; adults $=$ $14 \pm 5$ days; older adults $=9 \pm 1$ days). Adolescents and adults self-completed a paper version of the questionnaire at home (test-retest design). For adolescents and adults, the second questionnaire (retest) was delivered by a researcher when collecting the first questionnaire, so that replication was not possible. The researcher explained when the second questionnaire should be completed and wrote this date on the questionnaire. For older adults, structured interviews were conducted at home by trained researchers to collect data on both occasions.

\section{Criterion validity}

Eighty-one adolescents, 41 adults and 37 older adults, participated in the current criterion validity study. Adolescents were recruited via schools and adults and older adults were recruited via a city's public service department in Flanders (Belgium). Participants were asked to wear a movement monitor (activPAL ${ }^{\mathrm{mm}}$ ) for 7 days. Afterwards they were asked to complete an age-specific questionnaire on context-specific SB and its correlates.

For the adolescent group, principals of four schools randomly selected one class per school to participate in the current validity study (participation rate $=100 \%$ ). A researcher delivered the movement monitors and explained how to use them to the selected classes. The adolescents wore the movement monitor for seven consecutive days (starting the day after the explanation). On the $8^{\text {th }}$ day the monitors were recollected and the questionnaire was filled out at school under supervision of a researcher (paper-pencil; duration: 30-45 min).

Adults' contact information (full name, address and date of birth) was gathered via the public service department of the city of Sint-Niklaas (metropolitan city with approximately 73,000 inhabitants in Flanders). A randomly selected sample $(n=41)$ of adults willing to wear a movement monitor was contacted by telephone (participation rate $=64.2 \%)$. At the first appointment at the participants' homes, a researcher delivered the movement monitor and explained the purpose of the criterion validity study. The day after this visit, participants were asked to wear the movement monitor for seven consecutive days. On the $8^{\text {th }}$ day a researcher recollected the movement monitor at the participants' homes and the questionnaire was completed by the participants on the same day (paper-pencil; duration: $30-45 \mathrm{~min}$ ).

Contact information (full name, address and date of birth) from older adults was also gathered via the public service department of Sint-Niklaas. Individuals (65 years or older and living independently or in a service flat) were invited by telephone to take part in the study. Thirty-seven older adults agreed to participate and were subsequently visited at their home (participation rate $=$ $37.4 \%)$. At the first appointment at the participants' homes, a researcher delivered the movement monitor and explained the purpose of the criterion validity study. The day after this visit, participants were asked to wear the movement monitor for seven consecutive days. On the $8^{\text {th }}$ day a researcher recollected the movement monitor at the participants' homes and the questionnaire was completed on the same day through a structured interview led by a trained researcher (duration: 60-90 min).

\section{Measures}

\section{Questionnaires}

The questionnaires were developed to assess contextspecific SB and its correlates in three different age groups, namely adolescents, adults and older adults (see Additional files 1, 2, 3; Dutch questionnaires). In these questionnaires (and during structured interviews in case of older adults) participants received information about how they should report their behaviours, so that every period of sitting was only reported once (i.e. not duplicating SBs in case of simultaneous behaviours such as reading while listening to the radio).

The questionnaires consisted of three sections, namely (I) $\mathrm{SB}$, (II) potential correlates of context-specific SB and (III) sedentary-related equipment and simultaneous behaviour variables. The content of each section is described below and details are shown in Additional files 4, 5, 6. All these items were included in the test-retest reliability analyses.

I. Sedentary behaviour Context-specific SB (adolescents: 12 contexts; adults: 11 contexts; older adults: 12 contexts) was assessed based on the last-7-day SB questionnaire (SIT-Q-7d) [13]. The SIT-Q-7d (Dutch version) has fair-to-good test-retest reliability $(\mathrm{ICC}=0.68)$ and high criterion validity (Spearman's rho $=0.52$ ) when measuring total sedentary time (summing up all relevant $\mathrm{SB}$ contexts) in a Belgian adult population [13]. An 
overview of the included SB contexts in the current study for each age group is shown in Table 1.

Participants of all age groups were asked to indicate how much time they spent sitting/lying down during different SBs in the last 7 days (weekday and weekend day separately). For adults, work was included for 5 days. For each age group, the variable 'self-reported total sedentary time' was calculated by summing all midpoint values of the age-specific SB contexts (separately for weekday and weekend day). Self-reported total sedentary time was calculated for an average day, using the following formula: ((self-reported total sedentary time on a weekday $* 5)+($ self-reported total sedentary time on a weekend day $* 2$ ))/7.

II. Potential correlates of context-specific SB Potential (social-ecological) correlates of contextspecific SB were assessed for the following contexts: TV viewing, gaming, computer use, motorized transport and school in adolescents; TV viewing, computer use, motorized transport, occupation, household tasks and making phone calls in adults; and TV viewing, computer use, motorized transport, household tasks and making phone calls in older adults. The following items of the newly developed questionnaires were based on existing questionnaires: psychosocial items regarding TV, gaming, computer, occupation, household tasks and making phone calls, and motorized transport [23]; questions regarding modelling and/or rules for screen-related behaviours [24]; hours/min of physical education at school [25]; occupation-related information [26]. The answer categories of the psychosocial items (ranging from 'strongly disagree' to 'strongly agree' OR ranging from 'I consider it perfectly impossible' to 'I consider it perfectly possible') and modelling (e.g. ranging from 'never' to 'very often') all utilised five-point Likert scales or continuous scales. The items regarding rules for screen-related behaviours required dichotomous yes/no responses.

III.Sedentary-related equipment and simultaneous behaviour variables

The items related to sedentary-related equipment (i.e. (non-)portable electronic devices at home, in the bedroom) were based on an existing questionnaire

Table 1 Overview of the included sedentary behaviour contexts (behaviour-specific questions)

\begin{tabular}{|c|c|c|c|}
\hline & Adolescents & Adults & Older adults \\
\hline$\overline{T V}(\mathrm{WK}, \mathrm{WKND})^{(\mathrm{a})}$ & $\mathrm{V}$ & $\mathrm{V}$ & $\mathrm{V}$ \\
\hline Computer (WK, WKND) $)^{(\mathrm{a})}$ & V & V & V \\
\hline Sitting while reading $(\mathrm{WK}, \text { WKND) })^{(a)}$ & V & V & V \\
\hline Sitting for hobbies (WK, WKND) $)^{(a)}$ & V & V & V \\
\hline Sitting for socializing (WK, WKND) $)^{(a)}$ & V & V & V \\
\hline Sitting while listening to music (WK, WKND) ${ }^{(a)}$ & V & V & V \\
\hline Sitting during meals (WK, WKND) $)^{(a)}$ & V & V & V \\
\hline Motorized transport (to and from school, WK, WKND) (b) & V & - & - \\
\hline Motorized transport (to and from occupation, during occupation, WK, WKND) ${ }^{(b)}$ & - & V & - \\
\hline Motorized transport (WK, WKND) ${ }^{(b)}$ & - & - & V \\
\hline Sitting during school work at home (WK, WKND) $)^{(a)}$ & V & - & - \\
\hline Sitting while caring ((grand)children, family members,...) (WK, WKND) ${ }^{(a)}$ & - & V & V \\
\hline Sitting for using mobile phone (WK, WKND) $)^{(a)}$ & V & - & - \\
\hline Household tasks and making phone calls (WK, WKND) ${ }^{(a)}$ & - & V & - \\
\hline Making phone calls (WK, WKND) ${ }^{(a)}$ & - & - & V \\
\hline School $(W K)^{(a)}$ & V & - & - \\
\hline Occupation ${ }^{(c)}$ & - & V & - \\
\hline Household tasks (WK, WKND) ${ }^{(a)}$ & - & - & V \\
\hline Gaming (WK, WKND) ${ }^{(a)}$ & V & - & - \\
\hline Afternoon nap (WK, WKND) ${ }^{(a)}$ & - & - & V \\
\hline
\end{tabular}

WK weekdays, WKND weekend days, $V$ present in the age-specific questionnaire, - not present in the age-specific questionnaire Answer categories:

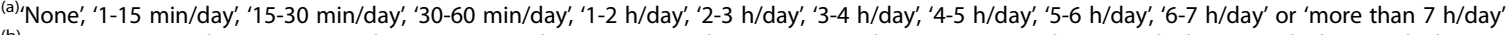

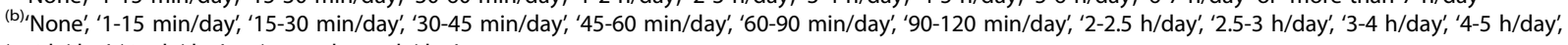

'5-6 h/day', '6-7 h/day' or 'more than $7 \mathrm{~h} /$ day'

(c)`Less than 2 h/day, '2-3 h/day', '3-4 h/day', '4-5 h/day,' '5-6 h/day', '6-7 h/day', '7-8 h/day', 'more than 8 h/day' 
[27] and categories of simultaneous behaviour (bivariate combinations of e.g. watching TV, using mobile phone, using computer/tablet, listening to music, having a conversation) using five-point Likert scales (ranging from 'never' to 'very often').

\section{Movement monitor (criterion measure for validity study)}

Total SB (weekdays and weekend days) was objectively measured using the activPAL ${ }^{\mathrm{Tu}}$ movement monitor (activPAL software version 6.4.1 and 7.2.29). This electronic inclinometer has already been validated in adolescents [28], adults [29] and older adults [30], and is recommended when measuring SB [31]. The activPAL ${ }^{\mathrm{Ta}}$ (15 grams, $53 \times 35 \times 7 \mathrm{~mm}$ ) was worn on the thigh and made waterproof prior to the wearing period by covering it with medical transparent tape (i.e. $3 \mathrm{M}$ Tegaderm ${ }^{\mathrm{Tm}}$, $3 \mathrm{M}$ Healthcare, St. Paul, MN). These waterproof attachments ensured that participants could wear the monitor during water activities (e.g. bathing and swimming), allowing continuous wear. Data from participants who wore the activ$\mathrm{PAL}^{\mathrm{Tm}}$ for at least 4 days (including 1 weekend day) was included in the analysis of the validity study. Participants recorded non-wear time (supplemented with reason) and the time of getting up and going to sleep in a diary. Objectively measured total SB (during waking hours) was also calculated for an average day, using the following formula: ((total SB on a weekday * 5) + (total SB on a weekend day $* 2)) / 7$.

Twelve adolescents were excluded from the analyses (technical problems activPAL ${ }^{\mathrm{mw}}: n=2$; not meeting inclusion criteria regarding number of wearing days: $n=2$; not wearing the activPAL $\left.{ }^{m}: n=8\right)$. Furthermore, 4 adolescents were not present during distribution of the movement monitor and 3 adolescents were absent for filling out the questionnaire on the $8^{\text {th }}$ day. In the adults group, 8 participants were excluded from the analyses (no questionnaire returned: $n=2$; ill while wearing monitor: $n=1$; not filling out the questionnaire on the $8^{\text {th }}$ day: $n=5)$. For older adults, 4 participants were excluded from the analyses (no/incorrect diary: $n=2$; not filling out the questionnaire on the $8^{\text {th }}$ day due to illness of participants: $n=2$ ). This resulted in a final sample of 62 adolescents, 33 adults and 33 older adults for the criterion validity study.

\section{Statistical analyses}

All analyses were conducted using IBM SPSS Statistics version 22 (SPSS Inc., Chicago, IL) and alpha levels of $\mathrm{p}<0.05$ were considered as significant.

\section{Participants' characteristics}

Sample characteristics of adolescents, adults and older adults participating in the test-retest reliability study or the criterion validity study were reported as means $\pm \mathrm{SD}$ (continuous variables) or percentages (categorical variables).

\section{Test-retest reliability}

Test-retest reliability was calculated for all included individual 'raw' items, separately for the three age groups. Furthermore, test-retest reliability was also assessed for self-reported total sedentary time on a weekday, weekend day and an average day. Three statistical tests were used for assessing the agreement between the first and second measurement. Kappa coefficients $(\mathrm{k})$ for dichotomous and qualitative variables, Intraclass Correlation Coefficients (ICC) for continuous, categorical five-point Likert scales, and percentage agreement (all items) were calculated. With regard to the ICC, two-way random effects single measures were calculated. Classification of reliability (ICC and $\mathrm{k}$ ) was interpreted as: 'poor' $(\leq 0.40)$, 'moderate' (0.41-0.60), 'good' (0.61-0.80) or 'excellent' $(\geq 0.81)[24,32]$. Furthermore, percentage agreement was measured, because ICCs and $\mathrm{K}$ are influenced by the presence of variability in response options [24, 33]. Classification of percentage agreement was based on the following criteria: 'poor' (<60\%), 'moderate' (60-74 \%), 'good' (75 \%-89 \%) or 'excellent' (90 \%-100 \%) [24]. Percentage agreement was only interpreted in 3 conditions: I) items with ICC or $\kappa<0.40$, but an agreement $>60 \%$, II) items with ICC or $\kappa<0.60$, but an agreement $>75 \%$ and III) items with ICC or $\kappa<0.80$, but an agreement $>$ $90 \%[24,34]$. Percentage agreement was also reported if the scale has zero variance items or if at least one variable in the analysis was a constant.

\section{Criterion validity}

The criterion validity of self-reported total sedentary time was determined separately for the three age groups, by calculating Spearman rank correlation coefficients $(\rho)$ between self-reported total sedentary time and activPALderived sedentary time (weekday, weekend day and average day separately). Classification of $\rho$ was interpreted as: 'low' (<0.30), 'moderate' (0.30-0.50) or 'high' (>0.50) [35]. In addition to the $\rho$, absolute agreement between selfreported and objectively measured sedentary time was measured by creating Bland-Altman plots [36]. These plots were created, based on linear regression analyses, through plotting the difference between self-reported total sedentary time and activPAL-derived sedentary time on the $y$-axis and the average of these self-reported and objectively measured sedentary time on the $\mathrm{x}$-axis (separately for weekday, weekend day and average day). In these plots the trend line of the regression analysis together with the $95 \%$ limits of agreement (LOA) were incorporated, so that conclusions could be made about the absolute agreement between the self-reported total sedentary time and the activPAL-derived sedentary time. However, this 
parametric approach is only applicable if residuals were normally distributed (examined by using KolmogorovSmirnov Test), which was only the case for all data of older adults. As a result, a nonparametric approach was used for all data (weekday, weekend day and average day) of adolescents and adults [36, 37]. In the context of this nonparametric approach, plots were created by plotting the difference between self-reported sedentary time and activPAL-derived sedentary time expressed as a percentage of activPAL-derived sedentary time on the y-axis. This percentage was plotted against activPAL-derived sedentary time on the $\mathrm{x}$-axis.

\section{Results}

\section{Participants' characteristics}

Sample characteristics (socio demographics) of adolescents, adults and older adults participating in the testretest reliability study or the criterion validity study are reported in Table 2 .

\section{Test-retest reliability}

Item-specific results determined in terms of ICC values, kappa values and/or percentage agreement, are shown in Additional file 4 (adolescents), Additional file 5 (adults) and Additional file 6 (older adults). In these additional files, usability of all the individual items for future research is reported. Furthermore, a summary of these results (for each part of the age-specific questionnaires) is reported in Table 3.

Fifteen, 14 and 25 items (for adolescents, adults and older adults respectively) had low ICC or kappa values, due to low variability in response options, but high percentage agreement (percentage agreement was thus interpreted instead of ICC or kappa values for these items). The test-retest reliability study indicated for adolescents, adults and older adults respectively that 89 items (67.93\%), 113 items $(68.90 \%)$ and 79 items $(66.38 \%)$ showed good to excellent reliability; 29 items (22.15\%), 37 items (22.56\%) and 25 items (21.01\%) showed moderate reliability. Furthermore, 13 items (9.92\%), 14 items (8.54\%) and 15 items (12.61\%) were found to have poor reliability for adolescents, adults and older adults respectively. With regards to the potential correlates of context-specific SB, the test-retest reliability study for adolescents, adults and older adults had relatively low percentages of items with poor reliability, namely $4.71 \%$ (4/85 items), $11.50 \%$ (13/113 items), and $14.49 \%$ (10/69 items) respectively. Furthermore, the results indicated that $62.50-95.66 \%$ of the contextspecific SBs had moderate-to-excellent reliability. More detailed information can be found in Table 3.

Next to the item-specific results, the test-retest reliability for self-reported total sedentary time indicated the following values for weekday, weekend day and an

Table 2 Sample characteristics of adolescents, adults and older adults included in the test-retest reliability study or the criterion validity study

\begin{tabular}{|c|c|c|c|c|c|c|}
\hline \multirow[b]{2}{*}{ Items } & \multicolumn{3}{|c|}{ Test-retest reliability } & \multicolumn{3}{|c|}{ Criterion validity } \\
\hline & Adolescents & Adults & Older adults & Adolescents & Adults & Older adults \\
\hline Numbers $(n)$ & 20 & 22 & 20 & 62 & 33 & 33 \\
\hline Age (years) [m (SD)] & $15.39(1.36)$ & $40.51(12.39)$ & $73.59(5.50)$ & $16.14(1.10)$ & $47.73(10.51)$ & $72.16(4.35)$ \\
\hline Male Gender (\%) & 57.90 & 45.50 & 50.00 & 41.90 & 36.40 & 60.60 \\
\hline \multicolumn{7}{|l|}{ Family situation } \\
\hline Traditional (mother \& father) (\%) & 75.00 & / & / & 71.00 & / & / \\
\hline Non-traditional (\%) & 25.00 & / & / & 29.00 & / & / \\
\hline Married (\%) & / & 54.50 & 85.00 & / & 66.70 & 69.70 \\
\hline Widow/widower (\%) & / & - & 15.00 & / & - & 9.10 \\
\hline Single (\%) & / & 4.50 & - & / & 6.10 & 21.20 \\
\hline Partner, but living apart (\%) & / & 9.10 & - & / & - & - \\
\hline Living with partner (\%) & / & 31.80 & - & / & 27.30 & - \\
\hline Educational level (\% tertiary) & / & 81.80 & 75.00 & / & 63.60 & 24.20 \\
\hline \multicolumn{7}{|l|}{ (Former) occupation } \\
\hline Household (\%) & / & / & 20.00 & / & / & 9.10 \\
\hline White collar (\%) & / & 85.70 & 50.00 & / & 67.70 & 42.40 \\
\hline Blue collar (\%) & / & 4.80 & 30.00 & / & 25.80 & 48.50 \\
\hline No occupation (\%) & / & 9.50 & / & / & 6.50 & / \\
\hline
\end{tabular}

Sample characteristics of participants in test-retest reliability study were assessed by taking into account the first measurement period / (not measured), - (not responded) 
Table 3 Results of the test-retest reliability study for adolescents, adults and older adults: overview per part of the age-specific questionnaires

\begin{tabular}{|c|c|c|c|c|c|c|c|}
\hline Sections of questionnaire (age-specific) & $\begin{array}{l}\text { Number } \\
\text { of items }\end{array}$ & ICC (range) & $\begin{array}{l}\text { Kappa } \\
\text { (range) }\end{array}$ & $\begin{array}{l}\text { Excellent } \\
\text { reliability } \\
\mathrm{n}(\%)\end{array}$ & $\begin{array}{l}\text { Good } \\
\text { reliability } \\
\mathrm{n}(\%)\end{array}$ & $\begin{array}{l}\text { Moderate } \\
\text { reliability } \\
\mathrm{n}(\%)\end{array}$ & $\begin{array}{l}\text { Poor } \\
\text { reliability } \\
\mathrm{n}(\%) \\
\end{array}$ \\
\hline \multicolumn{8}{|l|}{ Adolescents } \\
\hline Context-specific sedentary behaviours & 24 & $-0.06 ; 0.92$ & / & $2(8.33)$ & $3(12.50)$ & $10(41.67)$ & $9(37.50)$ \\
\hline Potential correlates of TV viewing & 24 & $0.49 ; 0.96$ & 0.44 & $10(41.67)$ & $10(41.67)$ & $4(16.66)$ & / \\
\hline Potential correlates of gaming & 19 & $0.24 ; 0.92$ & 0.63 & $4(21.05)$ & $8(42.11)$ & $6(31.58)$ & $1(5.26)$ \\
\hline Potential correlates of computer use & 18 & $0.16 ; 0.95$ & 0.49 & $7(38.89)$ & $5(27.78)$ & $5(27.78)$ & $1(5.55)$ \\
\hline Potential correlates of motorized transport & 21 & $0.18 ; 0.99$ & $0.30 ; 0.84$ & $8(38.10)$ & $8(38.10)$ & $3(14.28)$ & $2(9.52)$ \\
\hline Potential correlates of school & 3 & $0.57 ; 0.92$ & / & $1(33.33)$ & $1(33.33)$ & $1(33.33)$ & / \\
\hline Sedentary-related equipment & 16 & $0.38 ; 0.96$ & / & $13(81.25)$ & $3(18.75)$ & / & / \\
\hline Simultaneous behaviour & 6 & $0.71 ; 0.88$ & / & $4(66.67)$ & $2(33.33)$ & / & / \\
\hline Overall & 131 & $-0.06 ; 0.99$ & $0.30 ; 0.84$ & $49(37.41)$ & $40(30.53)$ & $29(22.14)$ & $13(9.92)$ \\
\hline \multicolumn{8}{|l|}{ Adults } \\
\hline Context-specific sedentary behaviours & 23 & $0.22 ; 0.95$ & / & $6(26.09)$ & $10(43.48)$ & $6(26.09)$ & $1(4.34)$ \\
\hline Potential correlates of TV viewing & 20 & $0.31 ; 0.93$ & / & $7(35.00)$ & $8(40.00)$ & $4(20.00)$ & $1(5.00)$ \\
\hline Potential correlates of computer use & 17 & $0.18 ; 0.92$ & / & $2(11.77)$ & $5(29.41)$ & $5(29.41)$ & $5(29.41)$ \\
\hline Potential correlates of motorized transport & 24 & $0.42 ; 1.00$ & $0.29 ; 1.00$ & $5(20.83)$ & $12(50.00)$ & $7(29.17)$ & / \\
\hline Potential correlates of occupation & 33 & $0.06 ; 0.94$ & $-0.07 ; 1.00$ & $6(18.18)$ & $14(42.43)$ & $9(27.27)$ & $4(12.12)$ \\
\hline Potential correlates of household tasks and making phone calls & 19 & $0.26 ; 0.85$ & $0.31 ; 0.70$ & $4(21.05)$ & $9(47.37)$ & $3(15.79)$ & $3(15.79)$ \\
\hline Sedentary-related equipment & 22 & $0.29 ; 1.00$ & / & $13(59.09)$ & $6(27.27)$ & $3(13.64)$ & / \\
\hline Simultaneous behaviour & 6 & $0.61 ; 0.87$ & / & $3(50.00)$ & $3(50.00)$ & / & / \\
\hline Overall & 164 & $0.06 ; 1.00$ & $-0.07 ; 1.00$ & $46(28.05)$ & $67(40.85)$ & $37(22.56)$ & $14(8.54)$ \\
\hline \multicolumn{8}{|l|}{ Older adults } \\
\hline Context-specific sedentary behaviours & 26 & $-0.13 ; 0.95$ & / & $9(34.62)$ & $7(26.92)$ & $5(19.23)$ & $5(19.23)$ \\
\hline Potential correlates of TV viewing & 19 & $-0.19 ; 1.00$ & / & $5(26.31)$ & $6(31.58)$ & $6(31.58)$ & $2(10.53)$ \\
\hline Potential correlates of computer use & 15 & $-0.15 ; 0.93$ & / & $4(26.67)$ & $3(20.00)$ & $5(33.33)$ & $3(20.00)$ \\
\hline Potential correlates of motorized transport & 17 & $-0.20 ; 0.91$ & 0.51 & $1(5.88)$ & $5(29.41)$ & $6(35.30)$ & $5(29.41)$ \\
\hline Potential correlates of household tasks and making phone calls & 18 & $-0.19 ; 0.88$ & $0.38 ; 1.00$ & $5(27.78)$ & $10(55.55)$ & $3(16.67)$ & / \\
\hline Sedentary-related equipment & 17 & $-0.07 ; 1.00$ & / & $12(70.59)$ & $5(29.41)$ & / & / \\
\hline Simultaneous behaviour & 7 & $0.78 ; 0.99$ & / & $7(100.00)$ & / & / & / \\
\hline Overall & 119 & $-0.20 ; 1.00$ & $0.38 ; 1.00$ & $43(36.13)$ & $36(30.25)$ & $25(21.01)$ & $15(12.61)$ \\
\hline
\end{tabular}

average day respectively: $\mathrm{ICC}=0.37$ (poor, $95 \%$ confidence interval $(\mathrm{CI})=-0.09 ; 0.70), \mathrm{ICC}=0.67($ good, $95 \%$ $\mathrm{CI}=0.32 ; 0.86$ ), $\mathrm{ICC}=0.45$ (moderate, $95 \% \mathrm{CI}=0.01$; 0.74 ) in adolescents; $\mathrm{ICC}=0.77$ (good, $95 \% \mathrm{CI}=0.52$; $0.90), \mathrm{ICC}=0.73$ (good, $95 \% \mathrm{CI}=0.45 ; 0.88), \mathrm{ICC}=0.77$ (good, $95 \% \mathrm{CI}=0.52 ; 0.90)$ in adults; $\mathrm{ICC}=0.80$ (good, $95 \% \mathrm{CI}=0.55 ; 0.92), \mathrm{ICC}=0.68$ (good, $95 \% \mathrm{CI}=0.34$; $0.86), \mathrm{ICC}=0.80$ (good, $95 \% \mathrm{CI}=0.55 ; 0.92)$ in older adults.

\section{Criterion validity}

An overview of the criterion validity results for adolescents, adults and older adults is presented in Table 4. Spearman rank correlation coefficients between self- reported total sedentary time and activPAL ${ }^{\mathrm{Tm}}$-derived sedentary time showed the following results for a weekday, weekend day and an average day respectively: $\rho=0.42$ (moderate, $95 \% \mathrm{CI}=0.19 ; 0.61$ ),$\rho=0.02$ (low, $95 \% \mathrm{CI}=-0.23 ; 0.27$ ), $\rho=0.29$ (low, $95 \% \mathrm{CI}=0.04$; 0.50 ) in adolescents; $\rho=0.52$ (high, $95 \% \mathrm{CI}=0.22$; 0.73), $\rho=0.06$ (low, $95 \% \mathrm{CI}=-0.29 ; 0.40$ ), $\rho=0.49$ (moderate, $95 \% \mathrm{CI}=0.18 ; 0.71$ ) in adults; $\rho=0.50$ (moderate, $95 \% \mathrm{CI}=0.19 ; 0.72$ ), $\rho=0.38$ (moderate, $95 \% \mathrm{CI}=0.04 ; 0.64$ ), $\rho=0.48$ (moderate, $95 \% \mathrm{CI}=$ $0.16 ; 0.71$ ) in older adults.

Adolescents and adults over-reported their total sedentary time compared to the criterion measurement $\left(\operatorname{activPAL}^{\mathrm{TM}}\right)$ for a weekday, weekend day and an average 
Table 4 Overview of the criterion validity results in adolescents, adults and older adults

\begin{tabular}{|c|c|c|c|c|c|c|c|}
\hline & \multirow[b]{2}{*}{$\begin{array}{l}\text { Self-reported total } \\
\text { sedentary time }\end{array}$} & \multirow[b]{2}{*}{$\begin{array}{l}\text { ActivPAL-derived } \\
\text { sedentary time }\end{array}$} & \multirow{2}{*}{$\begin{array}{l}\text { Spearman's } \\
\text { rho }(95 \% \mathrm{Cl})\end{array}$} & \multirow[t]{2}{*}{$p$-value } & \multicolumn{3}{|c|}{ Bland-Altman procedure } \\
\hline & & & & & $\begin{array}{l}\text { Regression equation: } \\
D=b_{0}+\left(b_{1}{ }^{*} A\right)\end{array}$ & $\begin{array}{l}\text { Standard deviation } \\
\text { of the residuals }\end{array}$ & $\mathrm{D}$ at $\mathrm{A}(95 \% \mathrm{LOA})$ \\
\hline \multicolumn{8}{|l|}{ Adolescents } \\
\hline Weekday & $971.85(287.65)$ & $618.11(65.13)$ & $0.42(0.19 ; 0.61)$ & 0.001 & / & / & / \\
\hline Weekend day & $810.73(351.56)$ & $567.98(96.02)$ & $0.02(-0.23 ; 0.27)$ & 0.861 & / & / & / \\
\hline Average day & $925.82(289.36)$ & $603.79(56.34)$ & $0.29(0.04 ; 0.50)$ & 0.023 & / & / & / \\
\hline \multicolumn{8}{|l|}{ Adults } \\
\hline Weekday & $648.18(270.12)$ & $479.18(156.26)$ & $0.52(0.22 ; 0.73)$ & 0.002 & / & / & / \\
\hline Weekend day & $512.27(238.02)$ & $447.76(99.07)$ & $0.06(-0.29 ; 0.40)$ & 0.743 & / & / & / \\
\hline Average day & $609.35(242.73)$ & $470.20(125.46)$ & $0.49(0.18 ; 0.71)$ & 0.004 & / & / & / \\
\hline \multicolumn{8}{|l|}{ Older adults } \\
\hline Weekday & $515.45(176.26)$ & $477.67(111.33)$ & $0.50(0.19 ; 0.72)$ & 0.003 & $-262.14+(0.60 \times A)$ & 139.48 & $35.80(-535.51 ; 11.24)$ \\
\hline Weekend day & $506.36(160.32)$ & $551.76(115.60)$ & $0.38(0.04 ; 0.64)$ & 0.030 & $-288.83+(0.46 \times A)$ & 147.17 & $-45.46(-577.29 ;-0.37)$ \\
\hline Average day & $512.86(162.08)$ & $498.84(102.47)$ & $0.48(0.16 ; 0.71)$ & 0.005 & $-287.19+(0.60 \times A)$ & 126.01 & $16.32(-534.18 ;-40.21)$ \\
\hline
\end{tabular}

Total sedentary times are expressed as minutes/day [mean (standard deviation)]

$D$ difference between self-reported total sedentary time and activPAL-derived sedentary time, $A$ average of self-reported total sedentary time and ActivPAL-

derived sedentary time, $b_{0}$ intercept, $b_{1}$ slope, $L O A$ limits of agreement ( $D \pm 1.96 \times$ standard deviation of the residuals), $C l$ confidence interval. $/ \mathrm{for}$ some variables,

Kolmogorov-Smirnov Test was significant, so that Bland-Altman procedures could not be performed

day respectively: $+57.05 \%,+46.29 \%,+53.34 \%$ in adolescents; $+40.40 \%,+19.15 \%,+32.89 \%$ in adults. Accordingly, both adolescents and adults over-reported their total sedentary time more for weekdays than for weekend days. Figure 1a, b and c (adolescents) and Fig. 2a, b and $c$ (adults) illustrate the criterion validity results in more detail (nonparametric approach). For adolescents and adults, weekend days (Figs. 1b and 2b) indicate higher variability at the lowest measured activPAL-derived sedentary time and lower variability at the highest measured activPAL-derived sedentary time. A decrease (expressed in $\%$ ) in over-reporting using the SB questionnaire was noticed when activPAL-derived sedentary time increased.

Older adults over-reported total sedentary time (except for a weekend day: $-6.24 \%$ ) compared to the activPAL- derived sedentary time, for a weekday and an average day respectively: $+10.10 \%,+4.11 \%$. In Fig. $3 a, b$ and $c$, in which the average of the two measurement methods was plotted against their difference, positive (significant) relationships were found for weekdays, weekend days and an average day. Differences between self-reported total sedentary time and activPAL-derived sedentary time were calculated by using the following formula recorded in Table 4: $\mathrm{D}=\mathrm{b}_{0}+\left(\mathrm{b}_{1} * \mathrm{~A}\right)$. The averages of the two measurement methods were: $496.56 \mathrm{~min} /$ weekday; $529.06 \mathrm{~min} /$ weekend day; and $505.85 \mathrm{~min} /$ average day. Accordingly, the mean difference between self-reported total sedentary time and activPAL-derived sedentary time for a weekday, weekend day and an average day respectively was: $35.80 \mathrm{~min} /$ day; $-45.46 \mathrm{~min} /$ day; $16.32 \mathrm{~min} /$ day. Figure 3a,
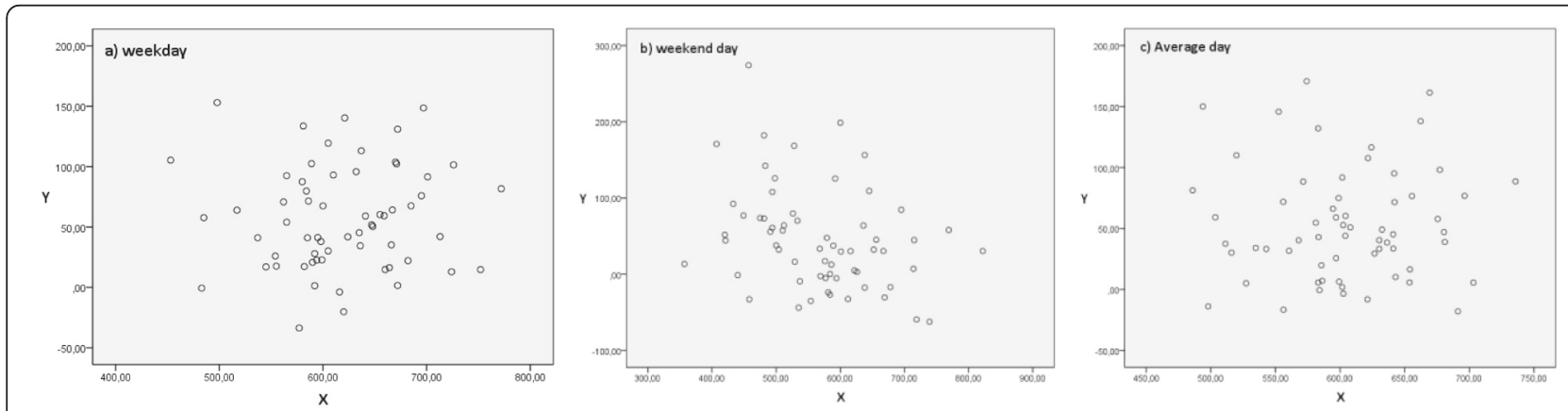

Legend: $Y=$ Difference between self-reported sedentary time and activPAL-derived sedentary time expressed as a percentage of activPALderived sedentary time ; $\mathrm{X}=$ activPAL-derived sedentary time (minutes/day)

Fig. 1 Non-parametric plots for adolescents: Difference between self-reported sedentary time and activPAL-derived sedentary time (\%) against activPAL-derived sedentary time, separately for a weekday, b weekend day, and c average day 

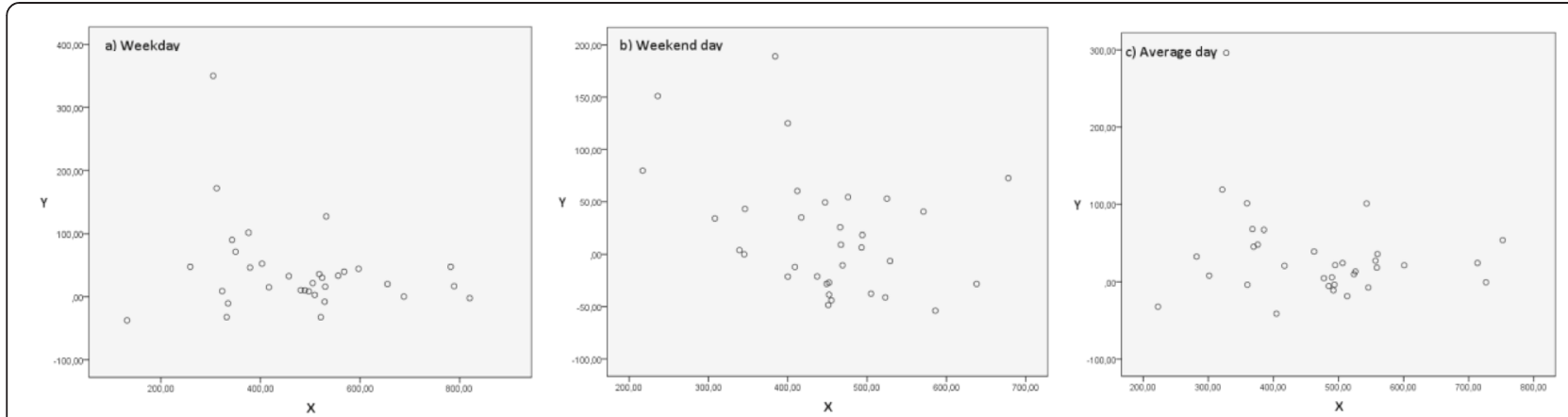

Legend: $Y=$ Difference between self-reported sedentary time and activPAL-derived sedentary time expressed as a percentage of activPALderived sedentary time; $\mathrm{X}=$ activPAL-derived sedentary time (minutes/day)

Fig. 2 Non-parametric plots for adults: Difference between self-reported sedentary time and activPAL-derived sedentary time (\%) against activPAL-derived sedentary time, separately for a weekday, b weekend day, and $\mathbf{c}$ average day

$\mathrm{b}$ and c revealed wide $95 \%$ limits of agreements $(3 \mathrm{a}=$ $-236.20 / 335.50 ; 3 b=-301.10 / 271.35 ; 3 c=-248.96 / 271.11$ ). These figures show that for high averages of self-reported and activPAL-derived sedentary time, self-reported total sedentary time overestimated the objectively measured sedentary time (weekday, weekend day and an average day).

\section{Discussion}

The current study examined the test-retest reliability and criterion validity of three newly developed questionnaires on context-specific SB and its potential correlates and on total sedentary time for adolescents, adults and older adults separately. These questionnaires are innovative as they include all relevant age-specific SB contexts $[7,11,13,14]$ together with potential correlates of context-specific SB.

Test-retest reliability was measured for self-reported total sedentary time and for context-specific SBs (apart for the three included age groups). The results for reliability of total sedentary time were comparable with previous research and revealed moderate-to-good reliability, except for total sedentary time on a weekday in adolescents [38]. Low test-retest reliability for sitting on a weekday in adolescents was also found in a study analyzing the International Physical Activity Questionnaire (short version) in youth [39].

Regarding the reliability of the context-specific SBs, TV viewing (for adolescents, adults and older adults) and computer use (for adults and older adults) were the most reliable items in the newly developed questionnaires. Present results are in line with previous findings in the literature $[7,10,40,41]$. This may be because TV viewing is an activity that is more structured and lasts for a longer uninterrupted time, compared to for example activities that occur more irregularly, such as motorized transport $[7,10]$. The lowest values for reliability were found for the following items: motorized transport in leisure time on weekend days and sitting during classes at school per day (adolescents), travelling in leisure time on weekend days (adults), sitting while listening to
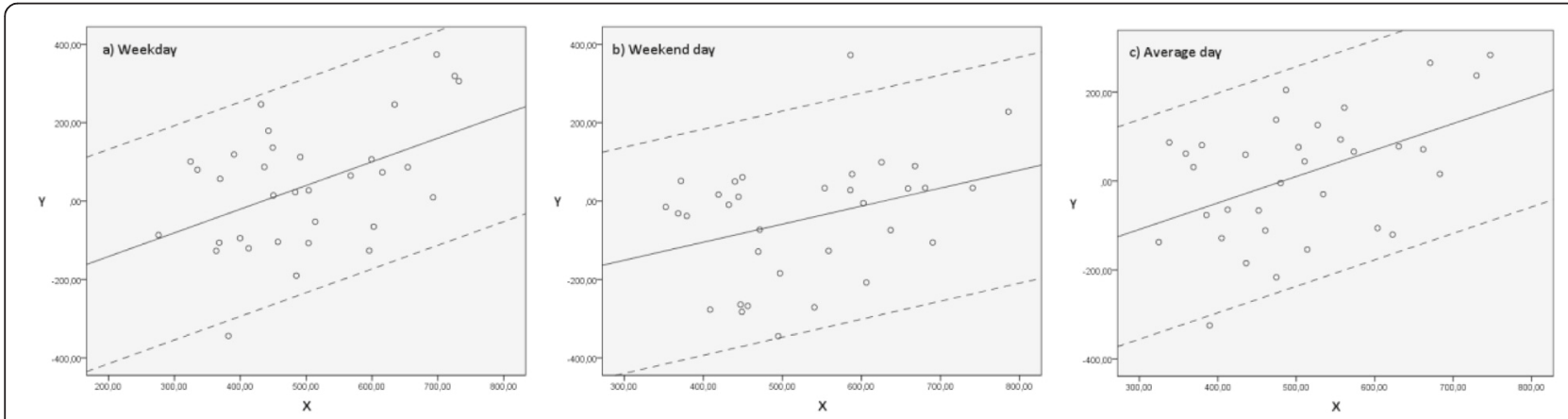

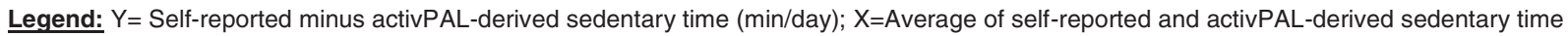
(min/day); $95 \%$ limits of agreement, LOA (dotted lines); mean difference (solid line).

Regression equations (weekday): $Y=0.60 * X-535.51$ (lower LOA); $Y=0.60 * X+11.24$ (upper LOA); $Y=0.60$ * $X-262.14$ (mean difference)

Regression equations (weekend day): $Y=0.46{ }^{*} X-577.29$ (lower LOA); $Y=0.46 * X-0.37$ (upper LOA); $Y=0.46{ }^{*} X-288.83$ (mean difference)

Regression equations (average day): $Y=0.60 * X \quad-534.18$ (lower LOA); $Y=0.60 * \quad-40.21$ (upper LOA); $Y=0.60$ * $X \quad-287.19$ (mean difference)

Fig. 3 Parametric Bland-Altman plots for older adults: Self-reported total sedentary time and activPAL-derived sedentary time, separately for a weekday, b weekend day, and $\mathbf{c}$ average day 
music and sitting for hobbies (older adults). An Australian study measuring the test-retest reliability of the 'adolescent sedentary activity questionnaire' also reported lower ICCs for travel (weekend ICCs $<$ weekday ICCs, except for high school girls) compared with the other included SB contexts [42]. Both the present findings (for adolescents and adults) and previous research in adolescents found poorer reliability results for travel during weekend days. This may be explained by the irregular pattern for this type of behaviour during weekend days. The low ICCs for some context-specific SBs might be explained by their between-week variability, as the test and retest did not record the same period [7]. However, the test-retest reliability for total sedentary time was found to be acceptable in all age groups. This suggests that the reliability of total sedentary time might not be considerably influenced by between-week variability, but the contexts of SB vary from week to week (e.g. one weekend self-reported sitting time may be high during motorized transport, but low the next week as the weather was good) [7]. This phenomenon was also present in a Belgian study, reporting good reliability for self-reported total sedentary time $(\mathrm{ICC}=0.77)$ [7].

Test-retest reliability was also measured for the potential correlates of context-specific $\mathrm{SB}$, sedentary-related equipment and simultaneous behaviour. In line with the present findings, two European studies in 10- to 12year-olds and adults reported good test-retest reliability for correlates of screen-viewing behaviour [24, 43]. In all three age groups no single item related to sedentaryrelated equipment or simultaneous behaviour showed poor reliability. The findings of sedentary-related equipment are in line with the results of a US study reporting ICCs ranging from 0.38-0.88 [27]. The potential correlates regarding TV viewing and school (adolescents), motorized transport (adults), and household tasks and making phone calls (older adults) showed the best reliability. By contrast, SB contexts with the lowest reliability results for potential correlates were motorized transport for adolescents, computer use for adults, and motorized transport for older adults. However, these SB contexts still showed relatively low percentages of items with poor reliability (2.35$7.25 \%)$. Potential correlates of context-specific SB with poor reliability should be used with caution and should not be used as single measures. Such items can however be useful when calculating scales (e.g. average score of items representing attitude towards computer use), but only if the internal consistency is acceptable.

Overall, moderate validity was found for self-reported total sedentary time measured in the three newly developed questionnaires [35]. Validity results for an average day were fair-to-moderate for adolescents and adults. This level of validity is higher than previously reported in youth [14, 44-46] and comparable [13, 47-49] or better $[14,49-53]$ than other validity results in adults. To our knowledge, with the exception of four studies $[13,48-50]$ that used activPAL devices, all of the other validity studies used accelerometers as objective measurement of sitting time. Furthermore, the validity was low for weekend days, but moderate-to-high for weekdays. These results indicate that when assessing total sedentary time, weekend SB may not be suitable as the sole measure. The study of Chastin et al. [50] compared sitting time (IPAQ long-form 7 days) with activPAL measures and found low validity in adults living in the UK (weekdays: $r=0.17$; weekend days: $r=0.01$ ) together with less accurately (underestimated) self-reported sitting time on weekend days compared with weekdays. The difference between weekend days and weekdays is in line with the findings of the current study and may be explained by less structured daily activities during weekend days compared to weekdays, making it more difficult to recall SB in the weekend. In the current study, validity results for older adults were moderate, and found to be comparable [54] or higher [7,55-58] than other studies in the same age group, except for the computer-delivered 24-h recall, i.e. MARCA (Adult version of the Multimedia Activity Recall for Children and Adolescents) [57]. The higher correlations in the current study can be explained by the use of activPALs as a criterion measure, while accelerometers were used in many of the latter studies. Furthermore, the Bland-Altman plots for older adults revealed that the error may be relative to the average of self-reported and activPAL-derived sedentary time, as the plots suggest to have a 'turning point' around $500 \mathrm{~min} /$ day on the $\mathrm{X}$-axis (i.e. low averages of self-reported and activPAL-derived sedentary time tend to have more underestimation).

Furthermore, the validity results revealed high percentages of over-reporting for a weekday, weekend day and an average day for adolescents and adults. Similar to our results, the SIT-Q-7d questionnaire overestimated total SB [13]. This may be the result of the inclusion of multiple contexts and thereby the possibility of doublereporting (due to simultaneous behaviour). Nowadays, adolescents and adults sometimes sit while doing several SBs simultaneously (e.g. watching TV and using a computer). Simultaneous behaviour is relatively new and can be present due to technological advances (e.g. the use of tablets, smartphones and laptops). The questionnaires attempted to avoid double-reporting by using several reminders regarding this issue. However, they may not have completely prevented double-reporting. The high percentages of over-reporting could also be caused by adolescents/adults who reported their sitting time more roughly, and therefore over-reported some SB activities as they may not have been capable to remember their SBs from the last seven days. Future studies and 
questionnaires should take simultaneous behaviour into account in the measurements of SB. An online tool measuring total SB by summing up all relevant domains/contexts of SB with a system of notifications on the screen when participants report unrealistic levels of total SB, is one of the possibilities to avoid over-reporting. Another possibility to tackle the consequences of simultaneous behaviour is the use of structured interviews. A US study by Matthews et al. [59] reported higher validity for adolescents and adults when an interviewer-led previous-day recall (PDR)' was compared with activPAL measurements $(\rho=0.60-0.81)$. Similar conclusions can be drawn in the current study, whereby higher validity and consequently lower percentages of over-reporting were found for the structured interviews among older adults than for the paper-pencil questionnaires completed by adolescents and adults, however, more research is needed to confirm that validity is higher when using interviews. Two methodological alterations may be useful to handle over-reporting of self-reported total sedentary time when using these newly developed questionnaires. First, self-reported total sedentary time can be truncated, so that this total sedentary time does not exceed the total waking time based on the average sleeping time reported in other studies enclosing participants with similar characteristics or questions about sleeping time in a sub-study. Secondly, the variables on simultaneous behaviour in the newly developed questionnaires can be used to identify behaviours frequently performed simultaneously, so that one of these SBs can be excluded in the subsequent calculation of self-reported total sedentary time.

A first limitation of the current study is that adults and older adults were free to choose if they would like to wear a movement monitor in the validity study. This may have resulted in self-selection bias (e.g. more motivated people) [60]. It is possible that these individuals were more accurate when filling out the questionnaires (both in reliability study as in validity study). Secondly, adolescents, adults and older adults filled out the questionnaires under different conditions (i.e. home environment versus school environment and paper-pencil versus structured interview), which may have reduced the comparability of the findings. Thirdly, the newly developed questionnaires were long (22-28 pages), so that administration duration was quite high (30-45 min for adolescents/adults and $60-90 \mathrm{~min}$ for older adults), however, this was necessary to capture context-specific information. Also, adolescents completed the questionnaire during school hours, however, no information about administration time is available for adults and older adults. Besides, occupational sitting time can be measured using the presented questionnaire. However, in many sectors (e.g. health, retail) work is not limited to weekdays, so for future research the inclusion of questions on occupational sitting time on weekends may be advised. Finally, the answer categories for sedentary time overlap, however, these are based on an existing SB questionnaire [13]. A major strength of the current study is the use of activPAL ${ }^{\mathrm{Tm}}$ as the criterion measure in the validity study. The use of the activ$\mathrm{PAL}^{\mathrm{ma}}$ for measuring SB has two major advantages: (I) continuous wearing ( $24 \mathrm{~h} /$ day), so limiting non-wear time, (II) classifying posture, so differentiating standing from sitting $[13,29]$. Secondly, the recall period in the questionnaire for the SB measurements (last seven days) was identical with the wearing period of the movement monitor, so measuring the same period. Thirdly, the majority of the content of the three newly developed questionnaires was identical for the three age groups, however, age-specific items were incorporated, so that potential age differences between SB contexts can be studied. Finally, the newly developed questionnaires may provide valuable information for future interventions about context-specific SB and its potential correlates.

\section{Conclusions}

All three newly developed questionnaires showed moderate validity for total sedentary time compared to existing questionnaires, except for weekend days in adolescents and adults [38]. However, high percentages of over-reporting of total sedentary time were found for adolescents and adults suggesting that estimations of total SB need to be interpreted with caution in these age groups. More research is needed to minimize over-reporting of total SB when using questionnaires in the future. Total sedentary time had moderate-to-good reliability. The reliability of most of the context-specific SBs was moderate-to-excellent, with screen-related behaviours (i.e. TV viewing and computer use) being the most reliable. Finally, most of the items (i.e. potential correlates of context-specific SBs, sedentaryrelated equipment and simultaneous behaviour) had moderate-to-excellent reliability. Overall, the newly developed age-specific questionnaires may enhance the knowledge on context-specific SB and its potential correlates.

\section{Additional files}

Additional file 1: Questionnaire adolescents (Dutch). (PDF 177 kb)

Additional file 2: Questionnaire adults (Dutch). (PDF 207 kb)

Additional file 3: Questionnaire older adults (Dutch). (PDF 248 kb)

Additional file 4: Results of the test-retest reliability study of the adolescents: Intraclass Correlation Coefficients (ICC), kappa and percentage agreement (item-specific). (PDF $405 \mathrm{~kb}$ )

Additional file 5: Results of the test-retest reliability study of the adults: Intraclass Correlation Coefficients (ICC), kappa and percentage agreement (item-specific). (PDF $424 \mathrm{~kb}$ )

Additional file 6: Results of the test-retest reliability study of the older adults: Intraclass Correlation Coefficients (ICC), kappa and percentage agreement (item-specific). (PDF 395 kb) 


\section{Abbreviations}

SB: Sedentary behaviour; METs: Metabolic equivalents; PA: Physical activity; TV: Television; ICC: Intraclass Correlation Coefficient; SIT-Q-7d: Last-7-day sedentary behaviour questionnaire; WK: Weekdays; WKND: Weekend days; SD: Standard deviation; $k$ : Kappa coefficient; $\rho$ : Spearman rank correlation coefficient; LOA: Limits of agreement; MARCA: Multimedia activity recall for children and adolescents; UK: United Kingdom; PDR: Previous-day recall; IPAQ: International Physical Activity questionnaire.

\section{Competing interests}

The authors declare that they have no competing interests.

\section{Authors' contributions}

CB performed data collection, statistical analyses, writing of the manuscript and revised the manuscript after receiving the comments of the co-authors KDC, GC and IDB supervised the study. KDC, WH, SFMC, GC and IDB contributed to the statistical analyses and interpretation of the data. All authors advised on interpretation and critically reviewed and approved the manuscript.

\section{Acknowledgments}

The authors wish to thank professor Marie Murphy (Ulster University) for proofreading the manuscript. Furthermore, we would like to thank all adolescents, adults and older adults who participated in the current study and the Fund for Scientific Research Flanders (FWO) for the funding (fund no. B/12530/01)

\section{Author details}

1 Department Movement and Sport Sciences, Ghent University, Watersportlaan 2, B-9000 Ghent, Belgium. ${ }^{2}$ School of Health and Life Science, Institute of Applied Health Research, Glasgow Caledonian University, Cowcaddens Road, Glasgow G4 OBA, Scotland, UK. ${ }^{3}$ Fund for Scientific Research Flanders (FWO), Egmontstraat 5, 1000 Brussels, Belgium.

\section{Received: 5 March 2015 Accepted: 8 September 2015 Published online: 17 September 2015}

\section{References}

1. Barnes J, Behrens TK, Benden ME, Biddle S, Bond D, Brassard P, et al. Letter to the Editor: Standardized use of the terms "sedentary" and "sedentary behaviours". Appl Physiol Nutr Me. 2012:37(3):540-2.

2. de Rezende LFM, Lopes MR, Rey-Lopez JP, Matsudo VKR, Luiz OD. Sedentary behavior and health outcomes: an overview of systematic reviews. Plos One. 2014;9(8):e105620

3. Chastin SF, Mandrichenko O, Skelton DA. The frequency of osteogenic activities and the pattern of intermittence between periods of physical activity and sedentary behaviour affects bone mineral content: the cross-sectional NHANES study. Bmc Public Health. 2014;14:4.

4. de Rezende LFM, Rey-Lopez JP, Matsudo VKR, Luiz OD. Sedentary behavior and health outcomes among older adults: a systematic review. Bmc Public Health. 2014;14:333.

5. Chastin SF, Mandrichenko O, Helbostadt JL, Skelton DA. Associations between objectively-measured sedentary behaviour and physical activity with bone mineral density in adults and older adults, the NHANES study. Bone. 2014;64:254-62.

6. Spittaels H, Van Cauwenberghe E, Verbestel V, De Meester F, Van Dyck D, Verloigne $\mathrm{M}$, et al. Objectively measured sedentary time and physical activity time across the lifespan: a cross-sectional study in four age groups. Int J Behav Nutr Phys Act. 2012;9:149.

7. Van Cauwenberg J, Van Holle V, De Bourdeaudhuij I, Owen N, Deforche B. Older adults' reporting of specific sedentary behaviors: validity and reliability. Bmc Public Health. 2014;14:734.

8. Ruiz JR, Ortega FB, Martinez-Gomez D, Labayen I, Moreno LA, De Bourdeaudhuij l, et al. Objectively measured physical activity and sedentary time in european adolescents the HELENA study. Am J Epidemiol. 2011;174(2):173-84.

9. Hamer M, Coombs N, Stamatakis E. Associations between objectively assessed and self-reported sedentary time with mental health in adults: an analysis of data from the Health Survey for England. BMJ open. 2014:4(3):e004580
10. Healy GN, Clark BK, Winkler EAH, Gardiner PA, Brown WJ, Matthews CE. Measurement of adults' sedentary time in population-based studies. Am J Prev Med. 2011;41(2):216-27.

11. Chastin SF, Schwarz U, Skelton DA. Development of a consensus taxonomy of sedentary behaviors (SIT): report of Delphi Round 1. Plos One 2013:8(12):e82313

12. Owen N, Sugiyama T, Eakin EE, Gardiner PA, Tremblay MS, Sallis JF. Adults' Sedentary Behavior Determinants and Interventions. Am J Prev Med. 2011;41(2):189-96

13. Wijndaele K, DEB I, Godino JG, Lynch BM, Griffin SJ, Westgate K, et al. Reliability and validity of a domain-specific last 7-d sedentary time questionnaire. Med Sci Sports Exerc. 2014;46(6):1248-60.

14. Chinapaw MJ, Slootmaker SM, Schuit AJ, van Zuidam M, van Mechelen W. Reliability and validity of the Activity Questionnaire for Adults and Adolescents (AQuAA). Bmc Med Res Methodol. 2009;9:58.

15. Wallmann-Sperlich B, Bucksch J, Hansen S, Schantz P, Froboese I. Sitting time in Germany: an analysis of socio-demographic and environmental correlates. Bmc Public Health. 2013;13:196.

16. Rhodes RE, Mark RS, Temmel CP. Adult sedentary behavior a systematic review. Am J Prev Med. 2012;42(3):E3-E28.

17. Uijtdewilligen L, Nauta J, Singh AS. Determinants of physical activity and sedentary behaviour in young people: a review and quality synthesis of prospective studies. Br J Sports Med. 2011;45(14):896-905.

18. Hardy LL, Hills AP, Timperio A, Cliff D, Lubans D, Morgan PJ, et al. A hitchhiker's guide to assessing sedentary behaviour among young people: Deciding what method to use. J Sci Med Sport. 2013;16(1):28-35.

19. Atkin AJ, Gorely T, Clemes SA, Yates T, Edwardson C, Brage S, et al. Methods of Measurement in epidemiology: sedentary Behaviour. Int J Epidemiol. 2012;41(5):1460-71.

20. McMurray RG, Ring KB, Treuth MS, Welk GJ, Pate RR, Schmitz KH, et al. Comparison of two approaches to structured physical activity surveys for adolescents. Med Sci Sports Exerc. 2004;36(12):2135-43.

21. Ajzen I. The Theory of Planned Behavior. Organ Behav Hum Dec. 1991;50(2):179-211.

22. Duncan MJ, Rashid M, Vandelanotte C, Cutumisu N, Plotnikoff RC. Development and reliability testing of a self-report instrument to measure the office layout as a correlate of occupational sitting. Int J Behav Nutr Phy. 2013:10:16.

23. Norman GJ, Sallis JF, Gaskins R. Comparability and reliability of paper- and computer-based measures of psychosocial constructs for adolescent physical activity and sedentary Behaviors. Res Q Exercise Sport. 2005;76(3):315-23

24. Singh AS, Vik FN, Chinapaw MJM, Uijtdewilligen L, Verloigne $M$ Fernandez-Alvira JM, et al. Test-retest reliability and construct validity of the ENERGY-child questionnaire on energy balance-related behaviours and their potential determinants: the ENERGY-project. Int J Behav Nutr Phy. 2011;8:136.

25. Lefevre J, Matton L, Wijndaele K, Duvigneaud N, Thomis M, Duquet W, et al. Validity of the Flemish Physical Activity Computerized Questionnaire (FPACQ). Med Sci Sport Exer. 2006;38(5):S562-2.

26. Spittaels H, Verloigne M, Gidlow C, Gloanec J, Titze S, Foster C, et al. Measuring physical activity-related environmental factors: reliability and predictive validity of the European environmental questionnaire ALPHA. Int J Behav Nutr Phy. 2010;7:48.

27. Rosenberg DE, Sallis JF, Kerr J, Maher J, Norman GJ, Durant N, et al. Brief scales to assess physical activity and sedentary equipment in the home. Int J Behav Nutr Phy. 2010;7:10.

28. Dowd KP, Harrington DM, Donnelly AE. Criterion and concurrent validity of the activPAL (TM) professional physical activity monitor in adolescent females. Plos One. 2012;7(10):e47633.

29. Kozey-Keadle S, Libertine A, Lyden K, Staudenmayer J, Freedson PS. Validation of Wearable Monitors for Assessing Sedentary Behavior. Med Sci Sport Exer. 2011;43(8):1561-7.

30. Grant PM, Dall PM, Mitchell SL, Granat MH. Activity-monitor accuracy in measuring step number and cadence in community-dwelling older adults. J Aging Phys Activ, 2008:16(2):201-14

31. Chastin SFM, Granat MH. Methods for objective measure, quantification and analysis of sedentary behaviour and inactivity. Gait Posture. 2010;31(1):82-6.

32. Dwyer GM, Hardy LL, Peat JK, Baur LA. The validity and reliability of a home environment preschool-age physical activity questionnaire (Pre-PAQ). Int J Behav Nutr Phy. 2011;8:86. 
33. Viera AJ, Garrett JM. Understanding interobserver agreement: the kappa statistic. Fam Med. 2005;37(5):360-3.

34. Saelens BE, Frank LD, Auffrey C, Whitaker RC, Burdette HL, Colabianchi N. Measuring Physical Environments of Parks and Playgrounds: EAPRS Instrument Development and Inter-Rater Reliability. J Phys Act Health. 2006;3:S190-207.

35. Cohen J. Statistical power analysis for the behavioral sciences. 2nd ed. New Jersey: Lawrence Erlbaum Associates; 1988

36. Bland JM, Altman DG. Measuring agreement in method comparison studies. Stat Methods Med Res. 1999:8(2):135-60

37. Van Holle V, De Bourdeaudhij I, Deforche B, van Cauwenberg J, Van Dyck D. Assessment of physical activity in older Belgian adults: validity and reliability of an adapted interview version of the long International Physical Activity Questionnaire (IPAQ-L). Bmc Public Health. in press.

38. Helmerhorst HJ, Brage S, Warren J, Besson H, Ekelund U. A systematic review of reliability and objective criterion-related validity of physical activity questionnaires. Int J Behav Nutr Phys Act. 2012;9:103.

39. Rangul V, Holmen TL, Kurtze N, Cuypers K, Midthjell K. Reliability and validity of two frequently used self-administered physical activity questionnaires in adolescents. Bmc Med Res Methodol. 2008;8:47.

40. Vereecken CA, Todd J, Roberts C, Mulvihill C, Maes L. Television viewing behaviour and associations with food habits in different countries. Public Health Nutr. 2006;9(2):244-50.

41. Liu Y, Wang M, Tynjala J, LV Y, Villberg J, Zhang Z, et al. Test-retest reliability of selected items of Health Behaviour in School-aged Children (HBSC) survey questionnaire in Beijing, China. BMC Med Res Methodol. 2010;10:73.

42. Hardy LL, Booth ML, Okely AD. The reliability of the Adolescent Sedentary Activity Questionnaire (ASAQ). Prev Med. 2007:45(1):71-4.

43. Singh AS, Chinapaw MJ, Uijtdewilligen L, Vik FN, van Lippevelde W, Fernandez-Alvira JM, et al. Test-retest reliability and construct validity of the ENERGY-parent questionnaire on parenting practices, energy balance-related behaviours and their potential behavioural determinants: the ENERGY-project. BMC Res Notes. 2012;5:434.

44. Wang $C$, Chen P, Zhuang J. Validity and reliability of international physical activity questionnaire-short form in Chinese youth. Res Q Exerc Sport. 2013;84:580-6.

45. Affuso O, Stevens J, Catellier D, McMurray RG, Ward DS, Lytle L, et al. Validity of self-reported leisure-time sedentary behavior in adolescents. J Negat Results Biomed. 2011;10:2.

46. Huang YJ, Wong SH, Salmon J. Reliability and validity of the modified Chinese version of the Children's Leisure Activities Study Survey (CLASS) questionnaire in assessing physical activity among Hong Kong children. Pediatr Exerc Sci. 2009;21 (3):339-53.

47. Cust AE, Armstrong BK, Smith BJ, Chau J, van der Ploeg HP, Bauman A. Self-reported confidence in recall as a predictor of validity and repeatability of physical activity questionnaire data. Epidemiol. 2009;20(3):433-41.

48. Clark BK, Winkler E, Healy GN, Gardiner PG, Dunstan DW, Owen N, et al. Adults' past-day recall of sedentary time: reliability, validity, and responsiveness. Med Sci Sport Exer. 2013;45(6):1198-207.

49. Kozey-Keadle S, Libertine A, Staudenmayer J, Freedson P. The feasibility of reducing and measuring sedentary time among overweight, non-exercising office workers. J Obes. 2012;2012(Article ID 282303):10.

50. Chastin SF, Culhane B, Dall PM. Comparison of self-reported measure of sitting time (IPAQ) with objective measurement (activPAL). Physiol Meas. 2014;35(11):2319-28.

51. Bull FC, Maslin TS, Armstrong T. Global physical activity questionnaire (GPAQ): nine country reliability and validity study. J Phys Act Health. 2009;6(6):790-804

52. Hagstromer M, Ainsworth BE, Oja P, Sjostrom M. Comparison of a subjective and an objective measure of physical activity in a population sample. J Phys Act Health. 2010;7(4):541-50.

53. Jacobi D, Charles MA, Tafflet M, Lommez A, Borys JM, Oppert JM. Relationships of self-reported physical activity domains with accelerometry recordings in French adults. Eur J Epidemiol. 2009;24(4):171-9.

54. Visser M, Koster A. Development of a questionnaire to assess sedentary time in older persons - a comparative study using accelerometry. BMC Geriatr. 2013;13(1):80

55. Gardiner PA, Clark BK, Healy GN, Eakin EG, Winkler EA, Owen N. Measuring older adults' sedentary time: reliability, validity, and responsiveness. Med Sci Sport Exer. 2011;43(11):2127-33.
56. Hekler EB, Buman MP, Haskell WL, Conway TL, Cain KL, Sallis JF, et al. Reliability and validity of CHAMPS self-reported sedentary-to-vigorous intensity physical activity in older adults. J Phys Act Health. 2012:9(2):225-36

57. Aguilar-Farias N, Brown WJ, Olds TS, Geeske Peeters GM. Validity of self-report methods for measuring sedentary behaviour in older adults. J Sci Med Sport. 2014 doi:10.1016/j.jsams.2014.08.004. [Epub ahead of print]

58. Scholes S, Coombs N, Pedisic Z, Mindell JS, Bauman A, Rowlands AV, et al. Age- and sex-specific criterion validity of the health survey for England physical activity and sedentary behavior assessment questionnaire as compared with accelerometry. Am J Epidemiol. 2014;179(12):1493-502.

59. Matthews CE, Keadle SK, Sampson J, Lyden K, Bowles HR, Moore SC, et al. Validation of a Previous-Day Recall Measure of Active and Sedentary Behaviors. Med Sci Sport Exer. 2013;45(8):1629-38.

60. Macfarlane D, Chan A, Cerin E. Examining the validity and reliability of the Chinese version of the International Physical Activity Questionnaire, long form (IPAQ-LC). Public Health Nutr. 2011;14(3):443-50.

\section{Submit your next manuscript to BioMed Central and take full advantage of:}

- Convenient online submission

- Thorough peer review

- No space constraints or color figure charges

- Immediate publication on acceptance

- Inclusion in PubMed, CAS, Scopus and Google Scholar

- Research which is freely available for redistribution 